\title{
Erratum to: Robert Whyttt (1714-1766): from dropsy in the brain to tuberculous meningitis
}

\author{
C. S. Breathnach
}

Published online: 18 May 2014

(C) Royal Academy of Medicine in Ireland 2014

\section{Erratum to: Ir J Med Sci}

\section{DOI 10.1007/s11845-014-1106-3}

- Page 5 Column 1 Line 6-'cause' should read 'course'; the resulting sentence should read:

$\mathrm{He}$ declared that a fever from water of the brain is easily distinguished from others by attending to the whole course of the disease and particularly to the pulse ... at first quick ... slow and irregular ... (p. 30) [3] ....and lastly acquires a greater frequency than ever. Besides, the screaming, squinting, and dilatation of the pupils rarely occur in other fevers (p. 31) [3].

- Page 5 Column 2 Line 15-'retired' should read 'returned'; the resulting sentence should read:

His health declined in 1825 and in 1831 he returned to Sherrington in Buckinghamshire, where he died in 1836.

- Page 5 Column 2 Line 23-'Table 1' should read 'Table 2'; the resulting sentence should read:

As Table 2 (after Price) [5] shows, in Dublin in 1936, the commonest cases occur between 9 months and 2 years.

The online version of the original article can be found under doi:10.1007/s11845-014-1106-3.

C. S. Breathnach $(\bowtie)$

School of Medicine and Medical Sciences, University College

Dublin, Belfield, Dublin 4, Ireland

e-mail: caoimhghin.breathnac@ucd.ie 